\title{
Psychometric properties of the Posttraumatic Growth Inventory in a sample of Brazilian university students
}

\author{
Propriedades psicométricas do Inventário de Crescimento Pós-Traumático em \\ uma amostra de estudantes universitários brasileiros
}

\author{
Thiago Loreto Garcia da Silva, ${ }^{1}$ Victoria Guimarães Ramos, ${ }^{1}$ Julia Candia Donat, ${ }^{1,2}$ Fernando Rainho de Oliveira, ${ }^{1,2}$ \\ Gustavo Gauer, ${ }^{3}$ Christian Haag Kristensen ${ }^{1,2}$
}

\begin{abstract}
Objective: To examine psychometric properties of the Brazilian version of the Posttraumatic Growth Inventory (PTGI).

Method: A total of 300 university students were evaluated though instruments that investigated trauma history, depression and posttraumatic symptoms, and personality traits through the Big Five model. Pearson's correlation was used to assess internal consistency, inter-item reliability and construct validity. Principal component analysis and confirmatory factor analysis were performed to investigate the factor structure of the PTGI.

Results: Results confirmed the original five-factor structure. The results showed good internal consistency for the total scale $(a=0.91)$ and its subscales, ranging from $a=0.85$ to $a=$ 0.70 . Also, evidence of construct and convergent validity was observed through correlations with posttraumatic and depression symptoms and personality measures.

Conclusions: These preliminary results suggest that the Brazilian PTGI is reliable and showed adequate evidence of validity.

Keywords: Psychological trauma, stress disorders, posttraumatic, validation studies, psychometrics.
\end{abstract}

\begin{abstract}
Resumo
Objetivo: O objetivo deste estudo é examinar as propriedades psicométricas da versão brasileira do Inventário de Crescimento Pós-Traumático (Posttraumatic Growth Inventory - PTGI).

Método: Foram avaliados 300 estudantes universitários através de instrumentos que investigaram histórico de trauma, sintomas pós-traumáticos e de depressão e traços de personalidade através do modelo Big Five. A correlação de Pearson foi utilizada para investigar consistência interna, confiabilidade entre itens e procedimentos de validade de construto. Análise de componentes principais e análise de fatores confirmatórios foram realizadas para investigar a estrutura fatorial do PTGI.

Resultados: Os resultados confirmaram a estrutura original de cinco fatores. Os resultados mostraram boa consistência interna para a escala total $(a=0.91)$ e suas subescalas, variando de $a=$ $0.85 \mathrm{a} a=0.70$. Além disso, evidências de validade de construto e convergente foram observadas através de correlações com sintomas pós-traumáticos e de depressão e medidas de personalidade.

Conclusões: Os resultados preliminares sugerem que o PTGI brasileiro é confiável e apresentou evidência de validade adequada.

Descritores: Trauma psicológico, transtornos de estresse, póstraumático, estudos de validação, psicometria.
\end{abstract}

\footnotetext{
${ }_{1}$ Pontifícia Universidade Católica do Rio Grande do Sul (PUCRS), Porto Alegre, RS, Brazil. 2 Núcleo de Estudos e Pesquisa em Trauma e Estresse (NEPTE), Programa de Pós-Graduação em Psicologia, PUCRS, Porto Alegre, RS, Brazil. ${ }^{3}$ Programa de Pós-Graduação em Psicologia, Universidade Federal do Rio Grande do Sul (UFRGS), Porto Alegre, RS, Brazil.

This article is based on the first author's dissertation entitled "Estudo das propriedades psicométricas da versão em português do Posttraumatic Growth Inventory" ("Study of the psychometric properties of the Brazilian version of the Posttraumatic Growth Inventory"), presented in 2016 at Pontifícia Universidade Católica do Rio Grande do Sul (PUCRS), Porto Alegre, RS, Brazil.

Submitted Apr 19 2017, accepted for publication Feb 122018.

Suggested citation: Silva TLG, Ramos VG, Donat JC, Oliveira FR, Gauer G, Kristensen CH. Psychometric properties of the Posttraumatic Growth Inventory in a sample of Brazilian university students. Trends Psychiatry Psychother. 2018;40(4):292-299. http://dx.doi.org/10.1590/2237-6089-2017-0050
} 


\section{Introduction}

Stress and trauma are widely studied in psychological science with the aim to understand the human ability to deal with adversity in life. Epidemiological studies suggest that potentially traumatic events, defined as stressful events that threat an individual's life, are common; most people will experience at least one such event in their lifespan. ${ }^{1}$ Since the classical studies from Selye, ${ }^{2}$ stress is conceptualized as an organism's response to aversive stimuli that challenge its homeostasis. Because the human response to stress is highly variable, depending on multiple biological, social and psychological factors, the approach focusing only on the negative and pathological consequences of stress has been criticized.

Most studies in the field are based on how adults deal with potentially stressful or traumatic events in a dysfunctional way, such as in posttraumatic stress disorder (PTSD) or major depression. That, however, does not take into account the wide range of human reactions to deal with adversity, ${ }^{3}$ especially when we consider that most people that face traumatic events do not present any disorder. ${ }^{1}$

Evidence from the emerging area of positive psychology suggests that some level of negative events and negative affect, besides being intrinsic to the human experience, might even play an essential role in mental health. ${ }^{4}$ Following the same rationale, it has been argued that the role of potentially traumatic events in development is not limited to initiating pathological responses, but might bring about possibilities of personal growth. This may be associated to the idea of flourishing through adversity, which, although present in varied religions, philosophies and cultures, only in the mid-1990s started to be studied from a scientific perspective. ${ }^{5,6}$ Studies from that perspective have labeled the phenomenon as benefit finding, stress-related growth, perceived benefits, thriving, and more recently, posttraumatic growth. ${ }^{7}$ The latter concept was introduced by Tedeschi \& Calhoun ${ }^{8}$ in an attempt to integrate the diverse definitions and to account for increasing evidence in the literature. The authors argue that posttraumatic growth best captures the essence of the phenomenon, by focusing on the outcome of major life crises, rather than on minor reactions to lower levels of stress.

The posttraumatic growth model proposes that, for the occurrence of growth, a "seismic" event is necessary, one that produces the level of stress necessary for the individual to feel like he should review his life assumptions and core beliefs. ${ }^{8}$ Such events can include an abrupt long-term marriage breakup, suddenly getting unemployed, or dealing with a difficult disease like HIV or cancer - way beyond the DSM- $5^{9}$ definition of traumatic events as life-threatening or serious physical injury situations. ${ }^{8}$

The Posttraumatic Growth Inventory (PTGI) is a selfreport measure aimed at quantifying the experience of growth, ${ }^{8}$ and is the most commonly used instrument in posttraumatic growth research. ${ }^{6,10}$ The PTGI was designed based on patients' reports found in the literature, especially those dealing with how they perceive growth and what has changed for the better in their lives. The original version of the PTGI comprises 21 items rated on a 6 -point Likert scale ranging from " 0 - I did not experience this change as a result of my crisis" to " 5 - I experienced this change to a very great degree as a result of my crisis." Examples of items are: "a willingness to express my emotions" and "I developed new interests." Internal consistency of the total PTGI was high $(a=0.90)$ and the test-retest reliability for the total PTGI was acceptable $(r=0.71) .{ }^{11}$ Factor analysis of the original instrument resulted in five domains of posttraumatic growth: 1) better appreciation of life and changing personal goals and priorities; 2) improvement in interpersonal relationships and a greater sense of intimacy with close ones; 3) recognition of new possibilities for living the life; 4) greater sense of strength and personal potentialities; $5)$ changes in spirituality. ${ }^{11}$

Despite the recognition that those five domains might not contemplate all existing possibilities of posttraumatic growth experiences, ${ }^{8}$ the five-factor structure has been replicated in the literature. ${ }^{12,13}$ However, different international studies have found other factor structures in their adapted versions. In the case of the Chilean ${ }^{14}$ and Bosnian ${ }^{15}$ versions, a three-factor structure better adjusted to the data: changes in philosophy of life, positive changes in self, and changes in interpersonal relation. A four-factor solution was found with data from Chinese cancer patients: self, spiritual visions, life orientation and an interpersonal/intrapersonal domain. ${ }^{16}$ Still, the original five-factor structure was found in numerous adaptations: European Portuguese, ${ }^{17}$ French, ${ }^{18}$ German, ${ }^{19}$ Italian, ${ }^{20}$ Australian ${ }^{21}$ and Persian. ${ }^{22}$ It has been suggested that such differences could indicate the influence of broad cultural views and narratives such as individualism or collectivism on subjective growth experience, ${ }^{23}$ but more research is needed to better identify such influences.

The PTGI has been used in several studies and encompasses a wide range of posttraumatic growth experiences observed in many populations and countries. Even though there is already a European Portuguese version of the PTGI, ${ }^{17,24}$ Brazilian Portuguese has different cultural, semantic and idiomatic influences. ${ }^{25}$ 
So, the present study aimed to assess the psychometric properties of a Brazilian version of the PTGI, including its factor structure, reliability (internal consistency) and validity measures (construct and convergent validity), in a non-clinical sample of Brazilian university students. To the authors' knowledge, no studies on posttraumatic growth have been conducted in Brazil to date, and the only PTGI adaptation to a Latin America language is the Chilean version. ${ }^{14}$ It is expected that exploring posttraumatic growth in Latin American cultures, such as in Brazil, will contribute to the understanding of the posttraumatic growth construct.

\section{Method}

\section{Participants}

The sample comprised 300 university students from different courses of a private university in Porto Alegre, southern Brazil. Only students who presented psychotic symptoms, history of neurological problems or substance-related disorders were considered ineligible to participate. Table 1 shows the sociodemographic

Table 1 - Demographic characteristics of participants $(n=300)$

\begin{tabular}{|c|c|c|}
\hline Characteristic & $\mathbf{n}$ & $\%$ \\
\hline \multicolumn{3}{|l|}{ Sex } \\
\hline Male & 104 & 34.7 \\
\hline Female & 196 & 65.3 \\
\hline Medication intake & 14 & 4.6 \\
\hline Antidepressants & 5 & 1.6 \\
\hline Anxiolytics & 2 & 0.6 \\
\hline Anticonvulsants & 4 & 1.3 \\
\hline Antipsychotics & 1 & 0.3 \\
\hline Stimulants & 4 & 1.3 \\
\hline Two or more types of medication & 3 & 1 \\
\hline \multicolumn{3}{|l|}{ Relationship status } \\
\hline Single & 255 & 85 \\
\hline Married & 36 & 12 \\
\hline Divorced & 9 & 3 \\
\hline \multicolumn{3}{|l|}{ Ethnicity/race } \\
\hline Caucasian & 276 & 92 \\
\hline Afro-descendent & 16 & 5.3 \\
\hline Other & 8 & 2.7 \\
\hline \multicolumn{3}{|l|}{ Socioeconomic status } \\
\hline Middle & 162 & 54 \\
\hline Upper & 72 & 24 \\
\hline Low & 66 & 22 \\
\hline Age (years), mean (SD) & 23.9 & 6.8 \\
\hline Years of study, mean (SD) & 14 & 2.5 \\
\hline
\end{tabular}

$\mathrm{SD}=$ standard deviation.

Data presented as $\mathrm{n}(\%)$, unless otherwise specified. data of the sample. Socioeconomic status was classified according to the Brazilian Economic Classification Criteria proposed by the Brazilian Association of Research Companies (Associação Brasileira de Empresas de Pesquisa - ABEP). ${ }^{26}$

\section{Instruments}

In addition to the PTGI, the instruments described below were employed.

\section{Sociodemographic questionnaire}

This instrument comprised general questions on the participants' age, gender, education level, use of medication and socioeconomic status. It also included questions about the participants' history of previous psychiatric disorders, in order to assess the exclusion criteria.

\section{Beck Depression Inventory $(B D I)^{27,28}$}

The BDI a self-report questionnaire consisting of 21 multiple-choice items. The result is classified, according to the sum of the scores of each item included, into one of four categories proposed (minimal, mild, moderate and severe depression). The Brazilian version of the instrument showed convergent validity with the Hamilton Depression Scale $(r=0.45 ; p<0.001)$ and a satisfactory reliability coefficient $(a=0.83)$ in depressed patients.

\section{Life Events Checklist (LEC-5) 29}

The LEC-5 contains 17 items referring to different types of traumatic events (car accident, assault, fire, grief, etc.). Participants indicate, for each type of event, if they have ever experienced, witnessed or heard about it. The second part contains eight objective questions about the characteristics of the worst traumatic event experienced, such as date of the event, its duration, and perceived intensity.

\section{Personality Assessment in the Model of the Big Five - Short Form ${ }^{30,31}$}

This instrument consists of 25 self-report items, each containing marker-adjectives for assessing personality according to the Big Five model. For each adjective, the participant assigns a score using a five-point Likert scale, ranging from $1=$ strongly disagree to 5 $=$ strongly agree. The original study reported adequate internal consistencies for the five subscales of the instrument, with Cronbach's alphas ranging from 0.78 to 0.88 . In the Brazilian population study, all subscales also showed adequate reliability coefficients, ranging from 0.83 to 0.61 . 
Posttraumatic Symptoms Checklist - Clinician Version $(P C L-C)^{32}$

To examine posttraumatic symptoms, the PCL-C was used, which is a self-report Likert scale. It contains 21 questions, one for each symptom of PTSD according to DSM-5. Individuals who score above the 38 cutoff point are considered symptomatic. At the present moment, psychometric properties of the current version of the PCL-C have not been established for the Brazilian population; the internal consistency of the instrument in the present study was considered acceptable $(a=0.81)$.

\section{Procedures}

Participants were recruited via poster announcements at the university. Students received two extra academic credit hours as a compensation for participating. Data collection was conducted individually. Upon agreeing to participate and signing a letter of consent, participants were asked to think about the most traumatic or negative and "life-changing" event that they had experienced, in order to answer the measures. After choosing the event, the participant was inquired on injuries or lifethreatening experiences related to the event in order to identify whether the event fulfilled DSM-5 criterion A for PTSD. Also, based on Lindstrom et al., ${ }^{33}$ two questions on perceived stress were asked, requiring the participant to rate, using a 7-point Likert scale, how disturbing or stressful the event was perceived 1 ) at the time it had occurred, and 2) at the time of data collection. Presentation order of the measures of traumatic events, stress symptoms and growth was counterbalanced to avoid order effects. The study was approved by the ethics committee for human research of Pontifícia Universidade Católica do Rio Grande do Sul (PUCRS), Porto Alegre, RS, Brazil.

\section{Data analysis}

Descriptive statistics were used to report population characteristics. In addition, several analyses were used to access psychometric properties of the of PTGI. Pearson's correlation was used for internal consistency, inter-item reliability and construct validity procedures. Exploratory factor analysis (EFA) through principal component analysis (PCA) with varimax rotation was used to assess the factor structure of the Brazilian version of the PTGI. In order to maintain the same parameters of the original study, only items loading > 0.5 in one factor and not loading $\geq 0.4$ in another factor were considered suitable.

Since some items had factor loadings in more than one factor, confirmatory factor analysis (CFA) was performed to verify that the instrument would preserve the same factor structure in the absence of the problematic items.
Because the sample size was not large enough for a random split, EFA and CFA were conducted on the same sample. Even though this procedure has limitations, it was considered to be useful as a preliminary result, since when CFA confirms EFA results in the same set of data, there are high chances that the same results will be confirmed in other samples as well. ${ }^{34}$

Because our sample was greater than 200 individuals, we used the chi-square test and the alternative methods for model fit. The alternative methods include the incremental fit index (IFI), comparative fit index (CFI), and the Tucker-Lewis index (TLI). These fit statistics indicated that the relative chi-square statistic and degrees of freedom (CMIN/ DF) should be roughly 2 ; alternative indices with a score above 0.90 correspond to a suitable model. The root mean square error of approximation (RMSEA) was nearly 0.06 , also indicating good model fit. After confirming the factor structure of the Brazilian version, the reliability of the instrument and its subscales was assessed using Cronbach's alpha coefficient. For construct validity, $t$ tests and univariate analysis of variance (ANOVA) were conducted to explore gender differences and the relation with growth and trauma severity. Analyses were performed using the Statistical Package for the Social Sciences (SPSS) version 21 and Analysis of Moment Structures (AMOS) version 21.

\section{Results}

\section{Traumatic/stressful life events}

Most participants in the sample (92\%) had experienced at least one traumatic event during life, and $68.9 \%$ had multiple exposures (mean $[\mathrm{M}]=2.1$, standard deviation $[S D]=3.09$, range: $0-11$ ). Half of the sample $(50.3 \%)$ chose a DSM-5 Criteria A-compatible event as worst trauma. The event considered worst by each participant was classified according to previous cross-cultural studies on posttraumatic growth and life event categories, ${ }^{12,35,36}$ as follows: self-injuries or illness (29.3\%); family or relational problems (33.7\%); grief $(21.7 \%)$; occupational or academic problems $(13.7 \%)$; and other $(1.7 \%)$. The time elapsed since the event ranged from 1 month to 28 years $(M=5.5, S D=5.5)$; $64 \%$ of the participants experienced the event in the last 5 years before the study, $14.9 \%$ in the last 10 years, $11.7 \%$ in the last 15 years, $7.6 \%$ in the last 20 years, and $2 \%$ in the last 28 years.

\section{Factor structure and internal consistency}

All 21 items correlated with each other significantly, ranging from $r=0.11, \mathrm{p}=0.017$ to $r=0.72, \mathrm{p}=$ 
0.0001 . All items also correlated significantly with the total score, ranging from $r=0.51, \mathrm{p}=0.0001$ to $r=0.75 \mathrm{p}=0.0001$. The EFA produced five factors with items corresponding to the same structure of the original instrument, accounting for $64.7 \%$ of the total variance. The variance explained and item loadings are summarized in Table 2.

In order to maintain the same parameters of the original study, only items loading $>0.5$ in one factor and not loading $\geq 0.4$ in another factor were considered. Therefore, three items (1,4 and 6$)$ had to be excluded from the Brazilian version. The 18-item of the Brazilian PTGI (PTGI-B) showed good reliability with Cronbach's alpha $(a=0.91)$. All subscales also showed reliability above acceptable: relating to others $=0.84$; new possibilities $=0.83$; personal strength $=0.70 ;$ spiritual change $=0.85$; and appreciation of life $=0.81$.

\section{Confirmatory factor analysis}

The factor structure of the 18-item PTGI-B was then tested using CFA. We tested a model with the 18 items and the five inter-related factors, proposed by Taku et al. ${ }^{12}$ as the best PTGI model. Our results showed good fit indices, confirming the PTGI-B model: CMIN/DF $=2.6, \mathrm{IFI}=0.92, \mathrm{CFI}=0.92, \mathrm{TLI}=0.90$, and RMSEA $=0.07$.

\section{Construct validity}

Construct validity of the PTGI has been verified in many studies investigating if the scale measures benefits that are unique to surviving a trauma, rather than learnings from ordinary life experiences. In our sample, PTGI-B total scores did not differ between trauma and non-trauma groups when using DSM-5 criteria to classify traumatic events $\left(t_{[298]}=-1.94, \mathrm{p}=0.053\right)$.

Table 2 - Factor loadings of the 21 items of the Posttraumatic Growth Inventory

\begin{tabular}{|c|c|c|c|c|c|}
\hline \multirow[b]{2}{*}{ Items and factors } & \multicolumn{5}{|c|}{ Factor loadings } \\
\hline & $\mathbf{I}$ & II & III & IV & $\mathbf{v}$ \\
\hline \multicolumn{6}{|l|}{ Factor I: Relating to others ( $16.9 \%$ of variance) } \\
\hline 6 - I more clearly see that I can count on people in times of trouble. & 0.62 & & & & 0.49 \\
\hline 8 - I have a greater sense of closeness with others. & 0.68 & & & & \\
\hline 9 - I am more willing to express my emotions. & 0.71 & & & & \\
\hline 15 - I have more compassion for others. & 0.56 & & & & \\
\hline 16 - I put more effort into my relationships. & 0.48 & & & & \\
\hline 20 - I learned a great deal about how wonderful people are. & 0.62 & & & & \\
\hline 21 - I better accept needing others. & 0.73 & & & & \\
\hline \multicolumn{6}{|l|}{ Factor II: New possibilities ( $16.6 \%$ of variance) } \\
\hline 1 - I changed my priorities about what is important in life. & & 0.51 & & & 0.48 \\
\hline 3 - I developed new interests. & & 0.82 & & & \\
\hline 4 - I have a greater feeling of self-reliance. & & 0.53 & 0.44 & & \\
\hline 7 - I established a new path for my life. & & 0.82 & & & \\
\hline 11 - I am able to do better things with my life. & & 0.56 & & & \\
\hline 14 - New opportunities are available which wouldn't have been otherwise. & & 0.69 & & & \\
\hline 17 - I am more likely to try to change things which need changing. & & 0.54 & & & \\
\hline \multicolumn{6}{|l|}{ Factor III: Personal strength ( $10.8 \%$ of variance) } \\
\hline 10 - I know better that I can handle difficulties. & & & 0.86 & & \\
\hline 12 - I am better able to accept the way things work out. & & & 0.79 & & \\
\hline 19 - I discovered that I'm stronger than I thought I was. & & & 0.53 & & \\
\hline \multicolumn{6}{|l|}{ Factor IV: Spiritual change (10.1\% of variance) } \\
\hline 5 - I have a better understanding of spiritual matters. & & & & 0.82 & \\
\hline 18 - I have a stronger religious faith. & & & & 0.86 & \\
\hline \multicolumn{6}{|l|}{ Factor V: Appreciation of life ( $10.1 \%$ of variance) } \\
\hline 2 - I have a greater appreciation for the value of my own life. & & & & & 0.77 \\
\hline 13 - I can better appreciate each day. & & & & & 0.62 \\
\hline
\end{tabular}


However, criterion A discriminated the total scores for two subscales: appreciation of life $\left(t_{[298]}=3.08, \mathrm{p}=\right.$ $0.002)$ and new possibilities $\left(t_{[298]}=-5.83, \mathrm{p}=0.001\right)$. Conversely, when using PCL-C as reference, total PTGI-B scores showed significant differences between the groups with high and low posttraumatic symptoms ( $t_{\text {[298] }}$ $=-23.4, p=0.001)$. Highly symptomatic individuals according to PCL-C also presented more differences in new possibilities $\left(t_{[298]}=-3.18, \mathrm{p}=0.002\right)$ and spiritual change $\left(t_{[298]}=-2.13, \mathrm{p}=0.03\right)$. Time since the event did not influence PTGI-B scores $(r=-0.55 \mathrm{p}=3.5)$, but was positively correlated with greater posttraumatic symptoms ( $r=-0.15, \mathrm{p}=0.008)$. Partial correlations controlling for the time elapsed since the event have shown that PTGI-B total scores were also correlated with re-experiencing $(r=0.18, \mathrm{p}=0.002)$ and avoidance symptoms $(r=0.12, \mathrm{p}=0.040)$. In addition to the symptoms, PTGI-B scores seem to associate with event severity, since it correlated with perceived suffering at the time that the event occurred $(r=0.19, \mathrm{p}=0.001)$, but not with event-related current suffering $(r=-0.053$, $p=0.36)$.

There were no significant differences between men $(M=1.05, S D=0.70)$ and women $(M=2.66, S D=$ 2.43) for PTGI-B total scores $\left(t_{[298]}=-1.83, \mathrm{p}=0.068\right)$. Differences in overall PTGI-B scores by gender were still not present when considering perceived trauma severity $\left(F_{[3.290]}=1.253, p=0.291\right)$ or when considering whether the trauma fulfilled criterion $A\left(F_{[1.296}\right]=1.349$, $\mathrm{p}=0.246)$.

In the original validation study, the authors proposed that the PTGI score was expected to be greater in people with higher socialization, extroversion and openness to experience personality traits. ${ }^{37}$ For concurrent validity, non-significant correlations with measures of depression have been used in the literature to bring some evidence that these are separate constructs and that PTGI does not merely measure absence of depression in the face of life adversity. ${ }^{19}$ Correlations with PTGI-B, personality and depression are presented in Table 3.

\section{Discussion}

The main purpose of this study was to investigate and assess the psychometric properties of the PTGI in a Brazilian non-clinical university sample. Despite PTGI factor structure differences among several populations (countries and sample types), the Brazilian version of the inventory has shown the same five-factor structure of the original version of the instrument. Moreover, reliability measures presented good internal consistency for the measure and its dimensions. Our results are very similar in terms of the total variance accounted for in the original PTGI $(60 \%) .{ }^{11}$

The similarity between the PTGI-B and the original American version leads to some considerations. There are complex differences in how cultures define or represent trauma, and how that shapes emotional and psychological reactions to events. ${ }^{38}$ Moreover, there is evidence indicating how those differences affect an individual's autobiographical memory of the traumatic event. ${ }^{39}$ In addition, cross-cultural comparisons between Brazil and USA indicate that these two cultures differ in terms of levels of individualism, acceptance of hierarchy, orientation to traditions and emotional expression. ${ }^{40}$ Despite such differences, the finding of the same fivefactor structure for PTGI-B suggests that, in terms of benefit finding or positive changes after a traumatic event, Brazilians might have very similar experiences

Table 3 - Relations between PTGI-B and personality

\begin{tabular}{|c|c|c|c|c|c|c|c|c|c|c|c|}
\hline & 1 & 2 & 3 & 4 & 5 & 6 & 7 & 8 & 9 & 10 & 11 \\
\hline 1. BDI - Total & - & & & & & & & & & & \\
\hline 2. PTGI - Total & 0.021 & - & & & & & & & & & \\
\hline 3. Extroversion & $-0.11^{*}$ & 0.04 & - & & & & & & & & \\
\hline 4. Socialization & $-0.19^{+}$ & $0.28^{+}$ & -0.003 & - & & & & & & & \\
\hline 5. Conscientiousness & $-0.20^{+}$ & $0.21^{+}$ & -0.04 & $0.34^{+}$ & - & & & & & & \\
\hline 6. Neuroticism & $0.64^{+}$ & -0.10 & $-0.15^{+}$ & $-0.18^{+}$ & $-0.11 *$ & - & & & & & \\
\hline 7. Openness to experience & -0.02 & 0.10 & $0.15^{+}$ & 0.06 & -0.04 & -0.06 & - & & & & \\
\hline 8. PTGI - New possibilities & $0.14^{*}$ & $0.81^{+}$ & 0.07 & $0.17^{+}$ & 0.10 & -0.07 & $0.17^{+}$ & - & & & \\
\hline 9. PTGI - Personal strength & $-0.12 *$ & $0.70^{+}$ & 0.006 & $0.20^{+}$ & $0.56^{+}$ & $-0.16^{+}$ & 0.09 & $0.46^{+}$ & - & & \\
\hline 10. PTGI - Appreciation of life & -0.001 & $0.71^{+}$ & -0.01 & $0.24^{+}$ & $0.17^{+}$ & -0.06 & 0.03 & $0.43^{+}$ & $0.48^{+}$ & - & \\
\hline 11. PTGI - Spiritual change & 0.05 & $0.58^{+}$ & 0.09 & $0.14 *$ & $0.19^{+}$ & -0.06 & 0.04 & $0.36^{+}$ & $0.31^{+}$ & $0.41^{+}$ & - \\
\hline 12. PTGI - Relation to others & 0.005 & $0.87^{+}$ & 0.01 & $0.26^{+}$ & $0.22^{+}$ & -0.03 & 0.06 & $0.60^{+}$ & $0.53^{+}$ & $0.57^{+}$ & $0.42^{+}$ \\
\hline
\end{tabular}

BDI = Beck Depression Inventory; PTGI = Posttraumatic Growth Inventory.

Correlation is significant at $* 0.05$ (1-tailed) and ${ }^{+} 0.01$ (1-tailed). 
to Americans. Still, the relations between personality and levels of growth have shown some differences in our sample compared to the original study. As the personality measures in this study were not the same used by Calhoun \& Tedeschi, ${ }^{37}$ direct comparisons are limited. As far as we know, until now, there are no studies on trauma meanings or autobiographical memories for trauma in Brazil, so future research and cross-cultural studies are warranted to help us understand the relations between cultural narratives, memory, personality and growth.

Despite many studies investigating the factor structure of the PTGI, only a few have investigated construct validity of the scale, ${ }^{18,19}$ and usually a restricted list of events is presented. ${ }^{41,42}$ As growth is hypothetically related to any "life crisis" experience, it is reasonable to expect that not only the life-threatening events listed on DSM- 5 should be targeted. Our results corroborate this hypothesis, since criterion A was incapable of discriminating levels of growth, while the level of perceived suffering was correlated. This finding not only supports the posttraumatic growth model but also raises the same questions on definition of trauma based on strict categories, as criticized by the mnemonic model of PTSD. ${ }^{43}$

On the relations between growth, posttraumatic symptoms and depression, our study corroborates previous findings. A meta-analytic study points out that growth is strongly related with re-experience and avoidance symptoms, but not with anxiety symptoms. In addition, posttraumatic growth has been associated with lower depression only in the first two years after trauma. ${ }^{44}$ As several items in the PCL-C refer to posttraumatic humor and anxiety symptoms, this could explain why, in our study, the PTGI did not correlate to total PCL-C scores, but strongly with re-experience and avoidance. As our study probed traumatic events that occurred within a very extended range of time, a nonsignificant relation with depression was expected.

This study has three main limitations. First, as mentioned, performing EFA and CFA in the same sample is not a standard procedure, so our CFA analysis findings are to be considered preliminary, as justified in the analysis section. Second, we did not impose a restriction to the range of time for the traumatic events chosen by the participants, a procedure that differs from the original study. This, despite increasing the ecological validity of the results, rules out the present study as a direct replication of the original. Third, our participants were university students from a private university, still a population of higher economic status when compared to other groups in Brazil. Further studies are certainly necessary to investigate growth experiences especially in low-income and clinical populations in the country.

Future research is needed in order to expand our understanding of cultural aspects of posttraumatic growth. We also expect that this validated measure can be used in clinical settings, developing theoretical and empirically-based interventions focused on human thriving after trauma. Nevertheless, our study presents evidence of the psychometric properties of PTGI-B, demonstrating that the scale is a useful tool for psychological assessment and treatment, and promotes greater attention by clinicians to the role of growth experiences in their clients' lives.

\section{Acknowledgements}

The authors are thankful for the support given by Conselho Nacional de Desenvolvimento Científico e Tecnológico (CNPq), Fundação de Amparo à Pesquisa do Estado do Rio Grande do Sul (FAPERGS) and Pontifícia Universidade Católica do Rio Grande do Sul (PUCRS). Thiago Loreto Garcia da Silva, Júlia Candia Donat, Fernando Rainho de Oliveira and Christian Haag Kristensen are recipients of scholarships from CNPq.

\section{Disclosure}

No conflicts of interest declared concerning the publication of this article.

\section{References}

1. Atwoli L, Stein DJ, Koenen KC, McLaughlin KA. Epidemiology of posttraumatic stress disorder: prevalence, correlates and consequences. Curr Opin Psychiatry. 2015;28:307-11.

2. Selye H. A syndrome produced by diverse nocuous agents. J Neuropsychiatry

Clin Neurosci. 1998;10:230-1.

3. Bonanno GA. Loss, truama, and human resilience: have we undersestimated the human capacity to thrive after extremely adverse events? Am Psychol. 2004;59:20-8.

4. Fredrickson BL. Updated thinking on positivity ratios. Am Psychol. 2013;68:814-22.

5. Tedeschi RG, Park CL, Calhoun LG, editors. Posttraumatic growth: positive changes in the aftermath of crisis. New Jersey: LEA; 1998.

6. Shakespeare-Finch J, Lurie-Beck J. A meta-analytic clarification of the relationship between posttraumatic growth and symptoms of posttraumatic distress disorder. J Anxiety Disord. 2014;28:2239.

7. Jayawickreme E, Blackie L. Posttraumatic growth as positive personality change: evidence, controversies and future directions. Eur J Pers. 2014;28:312-31.

8. Tedeschi RG, Calhoun LG, Taylor P. Posttraumatic growth: conceptual foundations and empirical evidence. Psychol Inq. 2004;15:1-18.

9. American Psychiatric Association. Diagnostic and statistical manual of mental disorders, 5th edition (DSM-5). Arlington: American Psychiatric Association; 2013. 
10. Linley AP, Joseph S. Positive change following trauma and adversity: a review. J Trauma Stress. 2004;17:11-21.

11. Tedeschi RG, Calhoun LG. The Posttraumatic Growth Inventory: measuring the positive legacy of trauma. J Trauma Stress. 1996; 9:455-71.

12. Taku K, Cann A, Calhoun LG, Tedeschi RG. The factor structure of the Posttraumatic Growth Inventory: a comparison of five models using confirmatory factor analysis. J Trauma Stress. 2008;21:158-64.

13. Tedeschi RG, Cann A, Taku K, Senol-Durak E, Calhoun LG. The Posttraumatic Growth Inventory: a revision integrating existential and spiritual change. J Trauma Stress. 2017;30:11-8.

14. Garcia FE, Solar FE, Melipillan R. Propiedades psicométricas del inventario de crecimiento postraumático en población chilena afectada por un desastre natural. Psiquis (Mexico). 2013;30:14351.

15. Powell S, Rosner R, Butollo W, Tedeschi RG, Calhoun LG. Posttraumatic growth after war: a study with former refugees and displaced people in Sarajevo. J Clin Psychol. 2003;59:71-83.

16. Ho SM, Chan CL, Ho RT. Posttraumatic growth in Chinese cancer survivors. Psychooncology. 2004;13:377-89.

17. Teixeira RJ, Pereira MG. Growth and the cancer caregiving experience: psychometric properties of the Portuguese Posttraumatic Growth Inventory. Fam Syst Health. 2013;31:38295.

18. Cadell S, Suarez E, Hemsworth D. Reliability and validity of a french version of the Posttraumatic Growth Inventory. Open ] Med Psychol. 2015;4:53-65.

19. Mack J, Herrberg M, Hetzel A, Wallesch CW, Bengel J, Schulz M, et al. The factorial and discriminant validity of the german version of the Post-Traumatic Growth Inventory in stroke patients. Neuropsychol Rehabil. 2015;25:216-32.

20. Prati G, Pietrantoni L. Italian adaptation and confirmatory factor analysis of the full and the short form of the Posttraumatic Growth Inventory. J Loss Trauma. 2014;19:12-22.

21. Morris BA, Shakespeare-Finch J, Rieck M, Newbery J. Multidimensional nature of posttraumatic growth in an australian population. J Trauma Stress. 2005;18:575-85.

22. Mehdi H, Maryam R, Farahnaz MS, Hamid AM, Hamidreza M, Mamak T. Validation of the persian version of the Posttraumatic Growth Inventory in patients with cancer. Payesh. 2015;14:467-73.

23. Weiss T, Berger R. Reliability and validity of a spanish version of the Posttraumatic Growth Inventory. Res Soc Work Pract. 2006;16:191-9.

24. Lisete GE. Estudo das características e qualidades psicométricas na população portuguesa dos instrumentos: Posttraumatic Growth Inventory, Core Beliefs Inventory, Event Related Rumination Inventory e Distress Disclosure Inventory [dissertation]. Braga: Universidade do Minho; 2008.

25. Silva TLG, Donat JC, Gauer G, Kristensen CH. Posttraumatic growth measures: Translation and adaptation of three selfreport instruments to Brazilian Portuguese. Rev Psiquiatr Clin. 2016;43:47-50.

26. Associação Brasileira de Empresas de Pesquisa (ABEP). Critério de Classificação Econômica Brasil [web site]. 2009. [cited 2017 Aug 17]. http://www.abep.org/criterio-brasil.

27. Beck AT, Steer RA, Ball R, Ranieri W. Comparison of Beck Depression Inventories-IA and -II in psychiatric outpatients. J Pers Assess. 1996;67:588-97.

28. Gomes-Oliveira MC, Gorenstein C, Neto FL, Andrade LH, Wang YP. Validation of the Brazilian Portuguese version of the Beck
Depression Inventory-II in a community sample. Rev Bras Psiquiatr. 2012:34:389-94.

29. Bovin MJ, Marx BP, Weathers FW, Gallagher MW, Rodriguez $P$ Schnurr PP, et al. Psychometric properties of the PTSD Checklist for Diagnostic and Statistical Manual of Mental Disorders-Fifth Edition (PCL-5) in veterans. Psychol Assess. 2016;28:1379-91.

30. Hutz CS, Nunes $\mathrm{CH}$, Silveira AD, Serra J, Anton M, Wieczorek LS. The development of the big five markers for personality assessment in Brazil. Psychology, reflection and criticism. 1998; $11: 395-411$

31. Filho HN, Machado WL, Teixeira MAP, Bandeira DR. Validity evidences of mini-markers for assessing the big five personality model. Psychology, theory and research. 2012;28:417-23.

32. Blevins CA, Weathers FW, Davis MT, Witte TK, Domino JL. The posttraumatic stress disorder checklist for DSM-5 (PCL-5): development and initial psychometric evaluation. J Trauma Stress. 2015;28:489-98.

33. Lindstrom CM, Cann A, Calhoun LG, Tedeschi RG. The relationship of core belief challenge, rumination, disclosure, and sociocultura elements to posttraumatic growth. Psychol Trauma Theory, Res Pract Policy. 2013;5:50-5.

34. van Prooijen JW, van der Kloot WA. Confirmatory analysis of exploratively obtained factor structures. Educ Psychol Meas. 2001;61:777-92.

35. Taku K. Commonly-defined and individually-defined posttraumatic growth in the US and Japan. Pers Individ Dif. Elsevier Ltd. 2011;51:188-93.

36. Taku K. Posttraumatic growth in american and japanese men: comparing levels of growth and perceptions of indicators of growth. Psychol Men Masc. 2013;14:423-32.

37. Calhoun LG, Tedeschi RG. Facilitating posttraumatic growth: a clinician's guide. New York: Routledge; 1999.

38. Wilson JP, Tang CS, editors. Cross-cultural assessment of psychological trauma and ptsd. Ohio: Singapore; 2007.

39. Jobson L, O'Kearney R. Cultural differences in autobiographical memory of trauma. Clin Psychol. 2006;10:89-98.

40. Hofstede G, Hofstede JH, Minkov M. Cultures and organizations: software of the mind. 3rd ed. USA: McGraw-Hill; 2010.

41. Osei-Bonsu PE, Weaver TL, Eisen SV., Vander Wal JS. Posttraumatic Growth Inventory: factor structure in the context of DSM-IV traumatic events. ISRN Psychiatry. 2012;2012:1-9.

42. Barton S, Boals A, Knowles L. Thinking about trauma: the unique contributions of event centrality and posttraumatic cognitions in predicting PTSD and posttraumatic growth. J Trauma Stress. 2013;26:718-26.

43. Rubin DC, Berntsen D, Bohni MK. A memory-based model of posttraumatic stress disorder: evaluating basic assumptions underlying the PTSD diagnosis. Psychol Rev. 2008;115:9851011.

44. Helgeson VS, Reynolds KA, Tomich PL. A meta-analytic review of benefit finding and growth. J Consult Clin Psychol. 2006;74:797816.

\section{Correspondence:}

Christian Haag Kristensen

Av. Ipiranga, 6681, Prédio 11, Sala 910

90619-900 - Porto Alegre, RS - Brazil

Tel. : +55 (51) 33534898

E-mail: christian.kristensen@pucrs.br 